\title{
Dr(a-) Polymorphism of Decay Accelerating Factor Biochemical, Functional, and Molecular Characterization and Production of Allele-specific Transfectants
}

\author{
Douglas M. Lublin, * E. Scott Thompson, * Annette M. Green, ${ }^{*}$ Cyril Levene," and Marilyn J. Telen* \\ ${ }^{*}$ Division of Laboratory Medicine, Departments of Pathology and Medicine, Washington University School of Medicine, \\ St. Louis, Missouri 63110; ${ }^{\ddagger}$ Division of Hematology/Oncology, Department of Medicine, Duke University \\ Medical Center, Durham, North Carolina 27710; and ${ }^{\S}$ Reference Laboratory for Immunohematology \\ and Blood Groups, Government Central Laboratories, Jerusalem, Israel
}

\section{Abstract}

The Dra antigen belongs to the Cromer-related blood group system, a series of antigens on decay accelerating factor (DAF), a glycosyl-phosphatidylinositol-anchored membrane protein that protects host cells from complement-mediated damage. We studied the rare inherited Dr(a-) phenotype to ascertain the associated biochemical and functional changes in DAF and to characterize the basis for this polymorphism. Radioimmunoassay and flow cytometric analysis of $\operatorname{Dr}(\mathrm{a}-)$ erythrocytes demonstrated $40 \%$ of normal surface expression of DAF but normal levels of several other glycosyl-phosphatidylinositol-anchored proteins, distinguishing this phenotype from that of paroxysmal nocturnal hemoglobinuria. Western blots confirmed this reduced DAF expression and indicated a slightly faster mobility of the molecule on SDS-PAGE. Despite the reduced DAF expression, $\operatorname{Dr}(\mathrm{a}-)$ erythrocytes functioned normally in the complement lysis sensitivity assay. Utilization of the polymerase chain reaction to amplify mononuclear cell genomic DNA from three unrelated $\operatorname{Dr}(\mathrm{a}-)$ individuals demonstrated that a point mutation underlies the $\operatorname{Dr}(\mathrm{a}-)$ phenotype: a $\mathrm{C}$ to $\mathrm{T}$ change in nucleotide 649 resulting in a serine $e^{165}$ to leucine change. This defines the Drb allele of DAF, which can be distinguished from Dra by a Taq I restriction fragment length polymorphism. We created transfected Chinese hamster ovary cell lines expressing either the $D r^{2}$ or the $D r^{b}$ allelic form of DAF. These allele-specific transfectants were tested by inhibition of hemagglutination or flow cytometry and confirmed the specificity of anti-Dra alloantisera. The allele-specific transfectants could form the basis of a new serological approach to immunohematology. (J. Clin. Invest. 1991.87:1945-1952.) Key words: complement • erythrocytes • Cromer-related blood group • glycosyl-phosphatidylinositol membrane anchor • flow cytometry

\section{Introduction}

Decay accelerating factor (DAF, $\left.{ }^{1} \mathrm{CD} 55\right)$ is a $70,000 M_{\mathrm{r}}$ membrane protein that protects host cells from damage by autolo-

Address reprint requests to Dr. Douglas M. Lublin, Department of Pathology, Washington University School of Medicine, 660 S. Euclid Avenue, Box 8118, St. Louis, MO 63110, or Dr. Marilyn J. Telen, Department of Medicine, Box 3387, Duke University Medical Center, Durham, NC 27710.

Received for publication 4 January 1991.

1. Abbreviations used in this paper: AST, allele-specific transfectant; CHO, Chinese hamster ovary cell line; CLS, complement lysis sensitivity; DAF, decay accelerating factor, GPI, glycosyl-phosphatidylinositol; LFA, lymphocyte function-associated; PCR, polymerase chain reaction; PNH, paroxysmal nocturnal hemoglobinuria; RFLP, restriction fragment length polymorphism; SCR, short consensus repeat.

J. Clin. Invest.

(c) The American Society for Clinical Investigation, Inc. $0021-9738 / 91 / 06 / 1945 / 08 \quad \$ 2.00$

Volume 87, June 1991, 1945-1952 gous complement (reviewed in 1). DAF is one member of the regulators of complement activation gene family, a group of linked genes on the long arm of human chromosome $1(2,3)$ that are comprised of multiple copies of a 60 -amino acid short consensus repeat (SCR). The products of these genes all serve to downregulate the activity of the complement system at the level of the $\mathrm{C} 3$ convertase. DAF is widely distributed in peripheral blood cells and in epithelial and endothelial tissues (4-7). It acts to prevent the assembly of $\mathrm{C} 3$ convertases and to dissociate preformed C3 convertases (8-11).

A novel structural feature of DAF is its attachment to the plasma membrane through a glycosyl-phosphatidylinositol (GPI) anchor $(12,13)$. The class of GPI-anchored membrane proteins (reviewed in 14,15 ) includes the complement-regulatory factors DAF, membrane inhibitor of reactive lysis (16-18), and C8-binding protein/homologous restriction factor $(19,20)$. The complement-regulatory function of DAF and the GPI anchoring both come into play in the disease paroxysmal nocturnal hemoglobinuria (PNH; reviewed in 21), an acquired hemolytic anemia. The underlying molecular basis of PNH is a failure to express any GPI-anchored proteins on the cell surface, presumably due to a defect in one of the enzymes responsible for synthesis or attachment of the GPI anchor. Therefore the affected blood cells in PNH patients fail to express the GPI-anchored complement-regulatory molecules and are abnormally sensitive to complement, with part of the increased sensitivity due to the absence of DAF in these cells $(9,22,23)$.

The cDNA $(24,25)$ and gene $(26)$ for human DAF have been cloned. Several polymorphisms have been identified in the noncoding regions of the DAF gene by restriction fragment length polymorphisms (RFLP) analysis $(3,27)$. Recently the Cromer blood group antigens (reviewed in 28) have been shown to reside on the DAF molecule (29), so that the serologically identified Cromer blood group alleles mark polymorphisms in the encoded DAF protein. These Cromer blood group phenotypes thus provide a basis for biochemical and functional investigation of alternate forms of DAF.

One rare Cromer phenotype is $\operatorname{Dr}(\mathrm{a}-)$, which has been found as a recessive trait in individuals in four unrelated Israeli families that all originally emigrated from the Bukharan region of Russia (30, 31; Levene, C., unpublished data). Erythrocytes of the $\operatorname{Dr}(\mathrm{a}-)$ phenotype lack expression of the $\mathrm{Dr}^{\mathrm{a}}$ antigen and have low expression of all of the other Cromer alleles including $\mathrm{Cr}^{\mathrm{a}}, \mathrm{Tc}^{\mathrm{a}}, \mathrm{Es}^{\mathrm{a}}, \mathrm{WES}^{\mathrm{b}}$, and IFC. No hematological abnormalities have been reported to be associated with the $\operatorname{Dr}\left(a^{-}\right)$phenotype.

In this study we investigated the biochemical expression of DAF in the $\operatorname{Dr}(\mathrm{a}-)$ phenotype and characterized the functional properties of this DAF variant. Furthermore, we have identified the molecular (nucleotide) change that defines the $\operatorname{Dr}\left(a^{-}\right)$ phenotype, found an allele-specific RFLP that can be used to phenotype individuals, and have created allele-specific transfectants that can be used to identify alloantibodies. 


\section{Methods}

Antibodies. Two rabbit polyclonal anti-DAF $(29,32)$ were used for radioimmunoassays, immunofluorescence, immunoprecipitation, and Western blots. Monoclonal antibodies 3.3.136 and K98 (33) (gift of Dr. Robert Knowles, Memorial Sloan Kettering, New York) directed against DAF were also used in radioimmunoassays and immunofluorescence. Monoclonal antibodies against acetylcholinesterase (34) (American Type Culture Collection, Rockville, MD) and CD58 (35) have been previously described. (Anti-CD58 was a gift from Dr. Timothy Springer, Dana Farber Cancer Institute, Boston.) Monoclonal antiCD59 (2/24D4) was used as part of investigations performed for the Second International Workshop on Monoclonal Antibodies Against Red Cells and Related Antigens (Lund, Sweden, 1990). Polyclonal anti-CD59 has also been previously described (16) and was provided by Dr. Charles Parker, University of Utah, Salt Lake City.

Radioimmunoassay of erythrocyte expression of GPI-anchored proteins. Radioimmunoassays to measure antibody reactivity with erythrocytes from $\operatorname{Dr}\left(\mathrm{a}^{+}\right)$or $\operatorname{Dr}\left(\mathrm{a}^{-}\right)$individuals were performed as previously described (36) except that radiolabeled Staphylococcal protein A was used to detect binding of rabbit antisera to DAF and CD59 (29).

Western blots. Western blotting of erythrocyte proteins was performed as previously described (37), except that antibody binding was detected using goat anti-rabbit IgG conjugated with alkaline phosphatase (Promega Biotec, Madison, WI) and a chromogenic substrate (a mixture of 5-bromo-4-chloro-3-indolyl-phosphate and nitro blue tetrazolium) prepared according to manufacturer's instructions.

Complement lysis sensitivity assays. The complement lysis sensitivity (CLS) assay was carried out as described (38). Briefly, erythrocytes were incubated with saturating amounts of human anti-I at $0^{\circ} \mathrm{C}$ and then incubated with varying dilutions of fresh human serum containing complement at $37^{\circ} \mathrm{C}$. Lysis of erythrocytes was measured by spectrophotometric analysis of hemoglobin released into the supernatant fluid. The CLS $\mathrm{H}_{50}$ is defined as the reciprocal of the dilution of serum used divided by the milliliter equivalents of serum required to obtain lysis of $50 \%$ of the cells.

Amplification of genomic DNA by PCR. Mononuclear cells were prepared from peripheral blood samples by Ficoll-Hypaque density gradient centrifugation (39). Genomic DNA was prepared from these cells by direct lysis in polymerase chain reaction (PCR) buffer with nonionic detergents and proteinase $K$ as described (40). PCR amplification of the genomic DNA with Taq polymerase was performed in a 50- $\mu$ l vol containing $0.2-1.0 \mu \mathrm{g}$ DNA, $1 \times$ PCR buffer $(50 \mathrm{mM} \mathrm{KCl}, 10$ $\mathrm{mM}$ Tris $\mathrm{pH} 8.3,1.5 \mathrm{mM} \mathrm{MgCl}_{2}, 0.01 \%$ gelatin), $200 \mu \mathrm{M}$ deoxynucleoside triphosphate mixture, $0.5 \mu \mathrm{M}$ of each primer, and 1.5 U Taq DNA polymerase (41). The primers of 17-26 nucleotides were synthesized on a synthesizer (Pharmacia Fine Chemicals, Piscataway, NJ) and were designed based on the sequence of the human DAF gene (26); in general, oligonucleotide pairs were synthesized to match sequences in the $5^{\prime}$ - and $3^{\prime}$-introns surrounding either one or several exons. The PCR was done with an initial denaturation of $94^{\circ} \mathrm{C}$ for $2 \mathrm{~min}, 35$ cycles consisting of denaturation at $94^{\circ} \mathrm{C}$ for $1 \mathrm{~min} /$ annealing at $45-55^{\circ} \mathrm{C}$ for $1 \mathrm{~min} /$ elongation at $72^{\circ} \mathrm{C}$ for $1-3 \mathrm{~min}$, and a final elongation step at $72^{\circ} \mathrm{C}$ for $10 \mathrm{~min}$.

DNA sequencing. PCR products were treated with T4 DNA polymerase to repair any possible ragged ends, extracted with phenol-chloroform, precipitated with ethanol, kinased with T4 polynucleotide kinase, and then purified on agarose gels and subcloned into the Eco RV site of the plasmid pBluescript KS+ (Stratagene, La Jolla, CA) by standard techniques (42). The double-stranded plasmid DNA (43) was sequenced with Sequenase DNA polymerase (44). Any differences from wild-type sequence were confirmed on several independent isolates to rule out a PCR or subcloning artifact.

RFLP analysis. PCR products were digested with Taq I restriction endonuclease in the PCR buffer at $65^{\circ} \mathrm{C}$ for $1.5 \mathrm{~h}$ under mineral oil, and then analyzed on an agarose gel with ethidium bromide staining.

Transfections. DAF cDNA was subcloned into the Eco RI site of the expression vector pSFFV.neo (45; a gift of S. Fine and D. Loh,
Washington University) containing the spleen focus-forming virus $5^{\prime}$ long terminal repeat, SV40 splicing and polyadenylation signals, and the neomycin-resistance gene. Chinese hamster ovary $(\mathrm{CHO})$ cells were transfected by lipid-mediated DNA transfection using $10 \mu \mathrm{g}$ DNA and $100 \mu \mathrm{g}$ Lipofectin (46). Positive cells were selected by resistance to the neomycin analogue $\mathrm{G} 418(0.25 \mathrm{mg} / \mathrm{ml}$ active drug) and individual subclones were produced by limiting dilution.

Biosynthetic labeling of cell lines and immunoprecipitations. $\mathrm{CHO}$ cell transfectants were plated $24 \mathrm{~h}$ before labeling in multiple $100-\mathrm{mm}$ dishes so as to be at $70 \%$ confluence at the time of labeling. The cells were washed, incubated in cysteine-free Ham's F-12 medium with 5\% dialyzed FCS for $1 \mathrm{~h}$, and then $100 \mu \mathrm{Ci} / \mathrm{ml}\left[{ }^{35} \mathrm{~S}\right]$ cysteine was added. For kinetic experiments, the cells were pulsed for the indicated time period and then the chase was begun by adding a 10,000-fold excess of unlabeled cysteine. At given time points a plate was processed by washing with cold PBS and solubilizing the cells in 1\% Triton X-114/Tris buffered-saline containing the protease inhibitors $2 \mathrm{mM}$ PMSF, $1 \mu \mathrm{M}$ pepstatin, and $100 \mathrm{U} / \mathrm{ml}$ aprotinin. A detergent extract (47) of the cell lysate was immunoprecipitated with rabbit polyclonal anti-DAF antiserum as described (48) and analyzed on $9 \%$ SDS-polyacrylamide gels under reducing conditions followed by fluorography.

Inhibition of hemagglutination. Agglutination of human erythrocytes with human alloantiserum plus antiglobulin (Coombs') reagent (Gamma Biologicals, Houston, TX) was carried out by standard serological techniques. Inhibition of hemagglutination was done by preincubating plasma samples or tissue culture supernates with the alloantiserum for $15 \mathrm{~min}$ at $37^{\circ} \mathrm{C}$ and then proceeding with the hemagglutination reaction as above.

Immunofluorescence. $\mathrm{CHO}$ transfectants were removed from tissue culture flasks by incubating for $2 \mathrm{~min}$ with trypsin-EDTA; preliminary experiments demonstrated that this brief treatment did not remove surface DAF, consistent with the previously described resistance of DAF to degradation by trypsin (49). Cells were stained with specific antibody followed by FITC-labeled second antibody and analyzed by flow cytometry to assess surface expression of DAF (50). Because human alloantisera gave high backgrounds on this analysis, the human alloantibodies were first partially purified from serum by absorption and elution from human erythrocytes using Elu-Kit II according to the manufacturer's directions (Gamma Biologicals).

\section{Results}

DAF expression on $\operatorname{Dr}\left(a^{-}\right)$erythrocytes. $\operatorname{Dr}\left(\mathrm{a}^{-}\right)$erythrocytes showed reduced hemagglutination with antibodies to non-D $\mathbf{r}^{\mathrm{a}}$ Cromer-related blood group antigens $(30,31)$, suggesting a reduced level of all Cromer-related antigens and hence of DAF. To confirm this directly, a radioimmunoassay was used to measure the levels of anti-DAF reactivity with $\operatorname{Dr}(\mathrm{a}+)$ and $\operatorname{Dr}\left(a^{-}\right)$erythrocytes. As shown in Table I, erythrocytes from a $\operatorname{Dr}\left(\mathrm{a}^{-}\right)$individual demonstrated reduced reactivity with both a rabbit polyclonal and one monoclonal anti-DAF (3.3.136), averaging $\sim 40 \%$ of normal in each case. Interestingly, a second monoclonal anti-DAF (K98) showed almost no reactivity with $\operatorname{Dr}(\mathrm{a}-)$ erythrocytes but reacted strongly with $\operatorname{Dr}(\mathrm{a}+)$ erythrocytes, suggesting that this monoclonal antibody might recognize an epitope at or near the polymorphic amino acids corresponding to the $\operatorname{Dr}(\mathrm{a}-)$ phenotype.

Measurements of surface DAF expression were also made by immunofluorescence. Erythrocytes from two additional $\operatorname{Dr}\left(\mathrm{a}^{-}\right)$and two $\operatorname{Dr}(\mathrm{a}+)$ individuals were treated with a different rabbit polyclonal anti-DAF and FITC-labeled second antibody and assessed by flow cytometry. The two $\operatorname{Dr}(\mathrm{a}-)$ erythrocytes yielded mean channel fluorescence values that were $32 \%$ and $48 \%$ of the average values for the $\operatorname{Dr}(\mathrm{a}+$ ) erythrocytes (data not shown). 
Table I. Reactivity of Normal and Dr(a-) Erythrocytes with Antibodies to DAF

\begin{tabular}{lccr}
\hline & \multicolumn{3}{c}{ Specific cpm bound } \\
\cline { 2 - 4 } Cell type & $\begin{array}{c}\text { Polyclonal } \\
\text { Rabbit anti-DAF }\end{array}$ & 3.3 .136 & K98 \\
\cline { 2 - 4 } Normal 1 & 2945 & 5246 & 3181 \\
Normal 2 & 3149 & 5566 & 4797 \\
Normal 3 & 3406 & 4980 & 4009 \\
Dr(a-) & 1488 & 2034 & 258 \\
\hline
\end{tabular}

Erythrocytes from normal, i.e., $\operatorname{Dr}(\mathrm{a}+)$, donors or a $\operatorname{Dr}(\mathrm{a}-)$ individual were treated with anti-DAF antibodies followed by appropriate radiolabeled second antibody or Staphylococcal protein A. Specific counts bound was calculated as the difference in bound radiolabel between test antibody and a negative control antibody (normal rabbit serum or a nonspecific monoclonal antibody).

To further characterize the DAF membrane protein from $\operatorname{Dr}(\mathrm{a}-)$ erythrocytes, Western blots were done with rabbit polyclonal anti-DAF. Western blots consistently demonstrated the markedly reduced expression of DAF by $\operatorname{Dr}(\mathrm{a}-)$ erythrocytes (Fig. 1). The apparent $M_{\mathrm{r}}$ of $\mathrm{DAF}$ on $\operatorname{Dr}(\mathrm{a}-$ ) erythrocytes, as judged by SDS-PAGE, was approximately the same as on $\operatorname{Dr}(\mathrm{a}+)$ erythrocytes; however, comparison of the two species on gels of differing polyacrylamide concentrations suggested a possible small decrease $(<2,000)$ in apparent $M_{\mathrm{r}}$ of the $\operatorname{Dr}(\mathrm{a}-)$ DAF (not shown).

Expression of GPI-anchored proteins on $\operatorname{Dr}(a-)$ erythro cytes. Having seen that $\operatorname{Dr}\left(\mathrm{a}^{-}\right)$erythrocytes express a reduced amount of a DAF species possessing near normal size, we next studied expression of other GPI-anchored membrane proteins to ascertain whether the defect was limited to DAF. Radioimmunoassay was used to measure reactivity with antibodies to three other GPI-anchored proteins: acetylcholinesterase, membrane inhibitor of reactive lysis (MIRL or CD59), and lymphocyte function-associated antigen 3 (LFA-3 or CD58). The $\operatorname{Dr}(\mathrm{a}-)$ erythrocytes showed a markedly reduced reactivity with antibodies to DAF, but they showed essentially normal reactivity with antibodies against the other three GPI-anchored proteins (Table II). By contrast, when cells from a patient with
Table II. Comparison of Reactivity of $\mathrm{Dr}(\mathrm{a}-)$ and PNH III Erythrocytes with Antibodies to GPI-linked Membrane Proteins

\begin{tabular}{lcc}
\hline & \multicolumn{2}{c}{ Percentage of normal binding } \\
\cline { 2 - 3 } \multicolumn{1}{c}{ Antibody type and specificity } & Dr(a-) & PNH III \\
\hline Polyclonal anti-DAF & $45 \%^{*}$ & $15 \%^{*}$ \\
Monoclonal 3.3-136 anti-DAF & $39 \%^{*}$ & $24 \%^{*}$ \\
Monoclonal K98 anti-DAF & $6 \%^{*}$ & $10 \%^{*}$ \\
Polyclonal anti-AChE & $98 \%^{*}$ & ND \\
Monoclonal anti-AChE & $95 \%$ & $5 \%^{*}$ \\
Polyclonal anti-CD59 & $99 \%^{*}$ & $23 \%^{*}$ \\
Monoclonal anti-CD59 & $100 \%$ & ND \\
Monoclonal anti-CD58 (LFA-3) & $88 \%$ & $39 \%^{*}$ \\
\end{tabular}

The reactivity of various antibodies against GPI-linked membrane proteins with erythrocytes from normal donors, a $\operatorname{Dr}(\mathrm{a}-)$ individual, or a PNH III individual was measured as specific counts bound as described in the legend to Table I. The results are listed as a percentage of the counts for normals.

* Indicates that difference is statistically significant, compared to normal Dr(a+) erythrocytes.

PNH were tested, they showed significantly reduced expression of all four GPI-anchored proteins, consistent with the known failure of surface expression of all GPI-anchored membrane proteins in PNH erythrocytes. These data clearly demonstrated the different phenotypes of $\operatorname{Dr}\left(\mathrm{a}^{-}\right)$and PNH erythrocytes.

CLS assay of $\operatorname{Dr}(a-)$ erythrocytes. Next the $\operatorname{Dr}(\mathrm{a}-)$ erythrocytes were tested for functional activity of DAF. DAF serves to protect cells from lysis by complement by inhibiting formation and accelerating the decay of the $C 3$ and C5 convertases (811 ), thus preventing the complement cascade from proceeding to final hemolysis. This was tested by the CLS assay of Rosse and Dacie (38). Dr(a-) erythrocytes gave a normal result in this assay, with values for $\mathrm{CLS}_{50}$ ranging from 1.35 (Fig. 2) to 1.8 , values well within the normal range. Even with reduced expression of DAF, the $\operatorname{Dr}(\mathrm{a}-)$ erythrocytes had no functional defect measured by this assay.

Single nucleotide change underlies $\operatorname{Dr}(a-)$ phenotype. The next step in the molecular characterization of the $\operatorname{Dr}\left(a^{-}\right)$phenotype was to identify the amino acid change or changes that

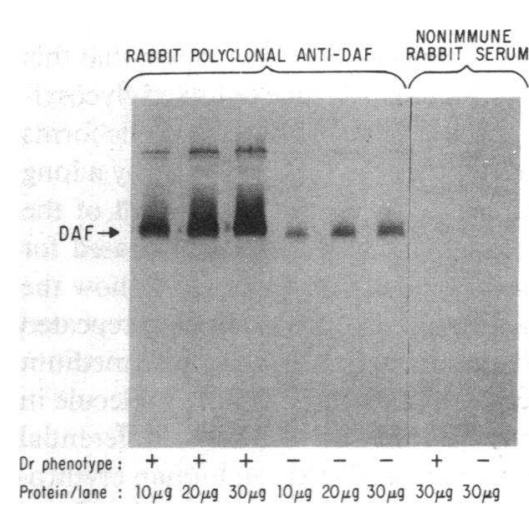
sponding to DAF. A

Figure 1. Western blot for DAF in human erythrocytes. Varying amounts of erythrocyte membranes (protein) lane) prepared from $\operatorname{Dr}(\mathrm{a}+)$ or $\operatorname{Dr}(\mathrm{a}-)$ individuals were subjected to Western blot analysis with rabbit polyclonal anti-human DAF or control nonimmune rabbit serum. The arrow marks the band corre-

minor band of approximately twice the $M_{\mathrm{r}}$ of DAF is also visualized; this DAF-2 species has been reported previously $(56,57)$.

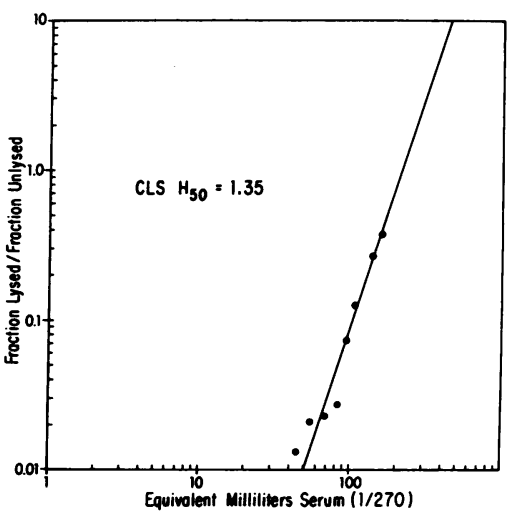

Figure 2. CLS assay of $\operatorname{Dr}\left(a_{-}\right)$erythrocytes. Erythrocytes from a $\operatorname{Dr}\left(a^{-}\right)$individual were incubated with antibody and varying dilutions of fresh human serum complement. The percent hemolyzed cells was measured by spectrophotometer, and the ratio of lysed to unlysed cells was then calculated and plotted on the $y$ axis versus equiv-

alent milliliters serum on the $x$ axis. The value of CLS $\mathrm{H}_{50}$ was found as described in Methods; in several experiments this value ranged from 1.35 to 1.8 , all within the normal range. 
determine the phenotype, including the antigenicity of the protein. This was accomplished by using PCR amplification to clone and sequence the coding region of membrane DAF. We had previously cloned the human DAF gene, which spans $\sim 40 \mathrm{~kb}$ and consists of 11 exons (26). The membrane form of DAF is encoded on nine exons (the two additional exons are the first exon encoding the 5 '-untranslated region and signal peptide and an alternatively spliced exon that is absent from the mRNA encoding membrane DAF; 25, 26). All of the exons encoding membrane DAF were amplified by PCR from genomic DNA of the original $\operatorname{Dr}\left(a^{-}\right)$propositus M.D. (30), and the PCR DNA products were subcloned into the vector pBluescript KS+ and sequenced. There was only a single nucleotide change in the entire coding region, and this is shown in Fig. 3: nucleotide 649 (numbering per reference 1) changes from $C$ to $\mathrm{T}$ in $\operatorname{Dr}(\mathrm{a}-)$ corresponding to a serine to leucine change at amino acid residue 165 which is in the third SCR.

Since the entire DNA sequence encoding the membrane DAF protein had been sequenced, the single nucleotide change found should correspond to the $\operatorname{Dr}\left(a^{-}\right)$phenotype. To confirm this finding, DNA from the identified region was amplified and sequenced in two unrelated $\operatorname{Dr}\left(\mathrm{a}^{-}\right)$individuals, and both showed the same nucleotide change as the propositus. This nucleotide change thus identifies these $\operatorname{Dr}(\mathrm{a}-)$ phenotype individuals as homozygous for a specific, identifiable allele of DAF which we designate $\mathrm{Dr}^{\mathrm{b}}$, a low-frequency antithetical allele to the high-frequency DAF allele $\mathrm{Dr}^{\mathrm{a}}$.

Taq I RFLP. The Dr ${ }^{\mathrm{b}}$ change alters the DAF nucleotide sequence 648-651 from TCGA to TTGA, thus removing a Taq I restriction site (see bottom of Fig. 3). This allele-specific RFLP can be used to type individuals at the Dr locus, and this is demonstrated in Fig. 4. A PCR-amplified DNA fragment of $\sim 1,250$ bp was produced from genomic DNA of either $\mathrm{Dr}^{\mathrm{a}}$ or $\mathrm{Dr}^{\mathrm{b}}$ individuals. This DNA was digested with Taq I and ana-

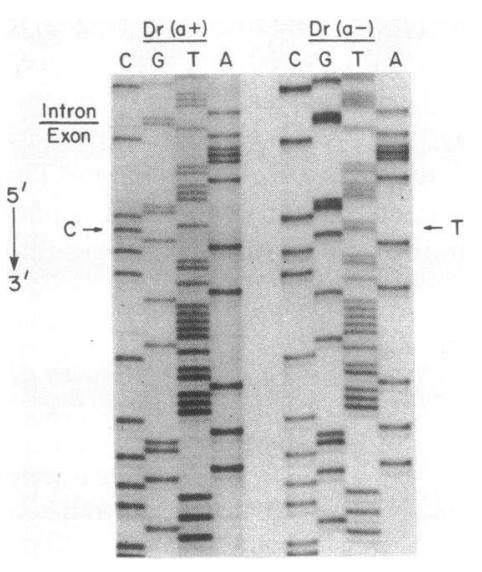

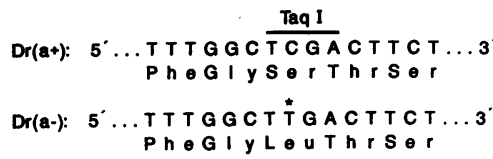

in this exon. The se-

quence of the two alleles of DAF from the region surrounding the polymorphic nucleotide is shown below, with that base marked with an asterisk. The Taq I restriction endonuclease site that is present in the $\operatorname{Dr}\left(\mathrm{a}^{+}\right)$sequence but absent in the $\operatorname{Dr}(\mathrm{a}-)$ allele is marked with an overline.

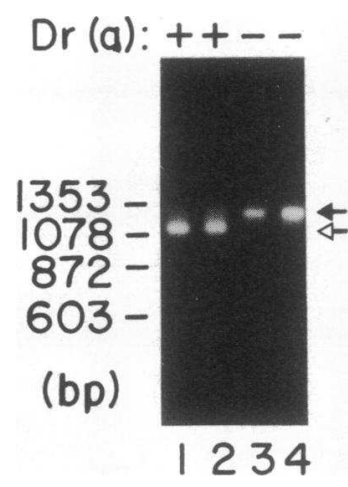

Figure 4. RFLP phenotyping of $\operatorname{Dr}(\mathrm{a}+)$ versus $\operatorname{Dr}\left(\mathrm{a}^{-}\right)$individuals. PCR-amplified genomic DNA including the $\operatorname{Dr}(\mathrm{a}+) / \operatorname{Dr}(\mathrm{a}-)$ polymorphic locus in exon 5 was produced as described in Fig. 3. Products of the PCR reaction from two individuals each of the $\operatorname{Dr}\left(\mathrm{a}^{+}\right)$and $\operatorname{Dr}\left(\mathrm{a}^{-}\right)$phenotypes migrated identically on agarose gels (not shown). The PCR DNA was digested with Taq I and analyzed by agarose gel electrophoresis, and a photograph of the ethidium bromide stained gel is shown. The solid arrow marks the band from $\operatorname{Dr}(\mathrm{a}-)$ individ-

uals (lanes 3 and 4 ) with no Taq I sites, whereas the open arrow marks the band from $\operatorname{Dr}(\mathrm{a}+$ ) individuals (lanes 1 and 2) that is produced by Taq I digestion (which also produces a smaller band of $116 \mathrm{bp}$ that is not visualized on this gel). Molecular size markers are shown on the left.

lyzed by agarose gel electrophoresis and ethidium bromide staining, demonstrating a single Taq I site in $\mathrm{Dr}^{\mathrm{a}} \mathrm{DNA}$ producing fragments of $\sim 1,150$ and 100 (the latter not visualized on this gel) and the Drb DNA with no Taq I site.

Allele-specific transfectants. For further analysis of this DAF polymorphism, we created allele-specific transfectants (AST). Just as allele-specific oligonucleotides permit the analysis of antigen or allele specificity (51), AST will permit the analysis of antibody specificity (see data below and Discussion). We had previously cloned the full-length (wild-type) DAF cDNA (24) that corresponds to the D $r^{2}$ allele. The cDNA for the $\mathrm{Dr}^{\mathrm{b}}$ allele was created by using oligonucleotide-directed in vitro mutagenesis (52) to introduce the single change at nucleotide 649 (C to T) into the $\mathrm{Dr}^{\mathrm{a}} \mathrm{cDNA}$. Both the $\mathrm{Dr}^{\mathrm{a}}$ and the $\mathrm{Dr}^{\mathrm{b}}$ allelic cDNA were subcloned into the expression vector pSFFV.neo (45) and transfected into CHO cells. Permanent transfectants were selected in the neomycin analogue G418. Individual subclones were produced by limiting dilution followed by screening for surface DAF expression by flow cytometry, and one high-expressing cell line of each allelic type was selected.

Biosynthesis and decay kinetics of DAF in AST. The biosynthesis of DAF in the Dra and $\mathrm{Dr}^{\mathrm{b}} \mathrm{AST}$ was studied in standard pulse-chase kinetic experiments. A short $\left[{ }^{35}\right.$ S $]$ cysteine pulse followed by a chase period demonstrates essentially identical kinetics for the pro-DAF species chasing into the higher $M_{\mathrm{r}}$ mature DAF species (Fig. $5 \mathrm{~A}$ ). Previous work has shown that this large $M_{\mathrm{r}}$ shift is mainly the result of extensive $O$-linked glycosylation (48). Next, to look at the stability of the two allelic forms of DAF, the AST were biosynthetically radiolabeled by a long pulse, chased in nonradioactive medium, to allow all of the intracellular DAF to get to the surface, and then chased for various time periods. The two allelic forms of DAF show the same decay kinetics (Fig. $5 \mathrm{~B}$ ). This experiment was repeated with the addition of $20 \%$ human serum to the chase medium (for the possible addition of any protease or other molecule in human serum that might be responsible for the differential stability of the polymorphic forms of DAF on human erythrocytes circulating in blood), but again there was no significant difference between the two DAF species (not shown). Thus, there is no evidence from these kinetic experiments in $\mathrm{CHO}$ 

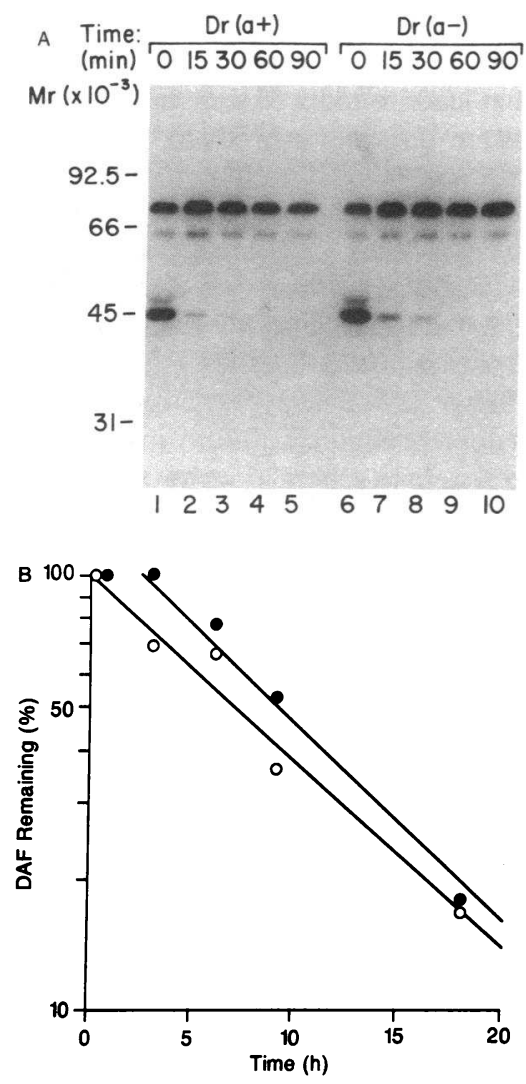
point and subsequent time points and analyzed as described above. Laser scanning densitometry of the fluorograph was used for the quantitation that is depicted in the graph $\left(0, \mathrm{Dr}^{\mathbf{c}} ; \bullet, \mathrm{Dr}^{\mathrm{b}}\right)$. Linear regression analysis yielded a $t_{1 / 2}$ value of $7.0 \mathrm{~h}$ for $\mathrm{Dr}^{2}$ and $6.6 \mathrm{~h}$ for $\mathrm{Dr}^{\mathrm{b}}$.

AST to explain the difference in the level of expression of the two Dr allelic forms of DAF in human erythrocytes.

Inhibition of anti-Dra hemagglutination by $A S T$. Since there was only a single nucleotide change in the coding region of the Drb allele of DAF, it was clearly implicated in the Dr polymorphism. In order to confirm this finding, we tested the DAF AST for reactivity with anti-Dra alloantibodies, the reagents used to define the actual polymorphism. Since the alloantibodies are normally identified in standard blood bank hemagglutination reactions, we used an inhibition of hemagglutination test. Material from the AST were used to inhibit alloantibody to $\mathrm{Dr}^{2}$, which was then assayed by hemagglutination. As seen in Table III, the Dra AST inhibited anti-D $r^{2}$ but neither the $\mathrm{Dr}^{\mathrm{b}}$ AST nor the control cell transfected with vector alone caused any inhibition. As further controls, material from the $\mathrm{HeLa}$ cell line or plasma from a $\mathrm{Dr}^{2}$ individual caused inhibition but plasma from a $\mathrm{Dr}^{\mathrm{b}}$ individual did not cause inhibition of hemagglutination, as expected.

Flow cytometric testing of AST. We also tested the AST in a direct flow cytometric analysis. Specifically, the alloantibodies were used to sensitize the AST, which were then stained with FITC-labeled second antibody and analyzed by flow cytometry. The results in Fig. 6 demonstrate that the AST show the expected Dr specificity, i.e., the alloanti-Dra recognizes the $\mathrm{Dr}^{2}$ but not the $\mathrm{Dr}^{\mathrm{b}}$ AST, whereas the rabbit polyclonal anti-DAF recognizes both AST. Thus, the AST testing allows us to con- firm the single amino acid change from $D r^{a}$ to $D r^{b}$ as the basis of the Dr polymorphism.

\section{Discussion}

This study has analyzed at the biochemical, functional, and molecular level the properties of a DAF polymorphic variant. This has produced several conclusions concerning DAF, and it has also led to a new approach to serological analysis in immunohematology through the use of allele-specific transfectants. At the protein level, the $\operatorname{Dr}\left(a^{-}\right)$phenotype was found to be due to reduced surface expression of a slightly altered form of DAF (based on its mobility on SDS-PAGE), with normal expression of other GPI-anchored membrane proteins. This form of DAF possesses normal complement regulatory activity as measured in the CLS assay. The actual molecular basis for the phenotype is a variant allele of DAF, named $\mathrm{Dr}^{\mathrm{b}}$, that encodes a single nucleotide (and amino acid) change from the common $\mathrm{Dr}^{2}$ allele. Finally, these two alleles of DAF were differentiated by an allele-specific Taq I RFLP, and were expressed in foreign cells to create AST that could be used in analyzing the specificity of human alloantiserum.

The Dr(a-) phenotype of DAF is one of eight identified genetic variants in the Cromer-related blood group system that resides on the DAF molecule (29). With the exception of the Inab phenotype, which lacks all surface expression of DAF, the $\operatorname{Dr}\left(a^{-}\right)$phenotype is the only variant that demonstrates reduced DAF expression by hemagglutination. Because the PNH phenotype results in reduced expression of all GPI-anchored membrane proteins, it was important to compare these two phenotypes. Radioimmunoassays measuring antibody reactivity against erythrocytes clearly demonstrated that the $\operatorname{Dr}(\mathrm{a}-)$ erythrocytes had an isolated defect in expression of DAF with normal expression of three other GPI-anchored proteins. This is in marked contrast to the PNH III phenotype with reduced expression of all of these GPI-anchored proteins (Table II). Western blot analysis confirmed the reduced expression of DAF protein, and suggested a slight alteration of SDS-PAGE mobility.

Previous investigations of the Inab phenotype had found a mild defect in complement regulatory activity as judged by the complement lysis sensitivity assay, comparable to PNH II cells $(53,54)$. It was therefore of interest to test $\operatorname{Dr}(\mathrm{a}-)$ erythrocytes,

Table III. Inhibition of Anti-Dra Hemagglutination by AST

\begin{tabular}{lc}
\multicolumn{1}{c}{ Sample } & Inhibition \\
\hline $\mathrm{CHO} / \mathrm{Dr}^{\mathbf{a}}$ & + \\
$\mathrm{CHO} / \mathrm{Dr}^{\mathbf{b}}$ & - \\
$\mathrm{CHO} / \mathrm{SFFV}$. neo & - \\
$\mathrm{HeLa}$ & + \\
$\mathrm{Dr}^{\mathbf{a}}$ plasma & + \\
$\mathrm{Dr}^{\mathbf{b}}$ plasma & -
\end{tabular}

Tissue culture supernatants from $\mathrm{CHO}$ cells transfected with $\mathrm{Dr}^{\mathrm{a}}$ or $\mathrm{Dr}^{\mathbf{b}}$ allele DAF cDNA or the expression vector SFFV.neo or from the HeLa cell line, or plasma of $\mathrm{Dr}^{\mathrm{a}}$ or $\mathrm{Dr}^{\mathrm{b}}$ homozygous individuals were incubated with alloantibody to $\mathrm{Dr}^{\mathrm{a}}$, then tested for hemagglutination of normal erythrocytes. Inhibition (+) or failure to inhibit (-) hemagglutination is scored. 


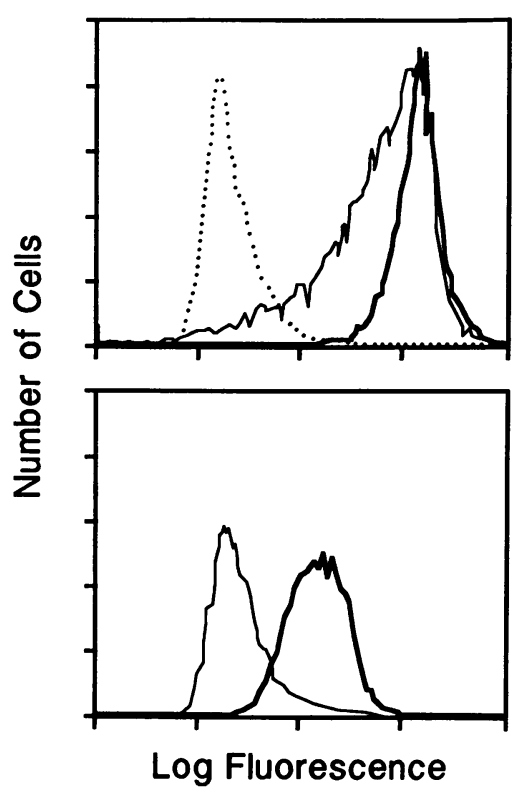

Figure 6. Assay using AST to assess alloantiserum specificity by flow cytometry. The $\mathrm{Dr}^{2}$ and $\mathrm{Dr}^{\mathrm{b}}$ AST were treated with human anti-Dra or with rabbit anti-human DAF, followed by appropriate FITC-labeled second antibody. They were analyzed by flow cytometry, and the panels show relative number of cells versus relative $\log$ fluorescence on a four decade scale. (Top) Drª AST (thick line) and $\mathrm{Dr}^{\mathrm{b}}$ AST (thin line) both show strong DAF expression as assessed with rabbit anti-human DAF compared to the negative control $\mathrm{CHO}$

cells transfected with vector alone (dotted line). (Bottom) Testing with human anti-Dra demonstrates reactivity with the $\mathrm{Dr}^{\mathrm{a}}$ AST (thick line) but not the $\mathrm{Dr}^{\mathrm{b}}$ AST (thin line).

which might have altered complement regulatory function either because of the reduced expression $(\sim 40 \%$ of normal) or because of the underlying minor structural alteration in the DAF molecule. In fact, the $\operatorname{Dr}(\mathrm{a}-)$ cells had a normal CLS titer (Fig. 2). Thus, neither the structural change nor the greater than twofold reduction in expression impair DAF function (at least as judged by this assay). This suggests that there might normally be an excess of required DAF on the surface of erythrocytes.

The remaining part of these studies focused on the actual molecular variation that underlies the Dr polymorphism: a single nucleotide change from $\mathrm{C}$ to $\mathrm{T}$ resulting in a single amino acid change from serine to leucine. This was the only nucleotide change present in the coding region of the DAF gene of the original $\operatorname{Dr}(\mathrm{a}-)$ propositus, and the same change was found in two other unrelated $\operatorname{Dr}(\mathrm{a}-)$ individuals. The presence of this nucleotide sequence can then be used to identify the DAF allele present in these individuals, which we designate $\mathrm{Dr}^{\mathrm{b}}$. This is the first case, to our knowledge, where an erythrocyte antigen was first defined at the nucleotide level and not by the discovery of an alloantiserum of the appropriate specificity. This method of antigen identification at the DNA level will be especially useful for low-frequency alleles where it is very unlikely that an alloantiserum will be found.

Expression of the two Dr alleles in CHO cells to create AST has allowed us to probe the properties confered by the allelic difference, as well as to set up a system for alloantibody identification (see below). The pulse-chase experiments showed no difference between the two allelic forms of DAF as far as the kinetics of processing of DAF from a precursor form to the mature, glycosylated form or in the kinetics of decay. Therefore, the polymorphic difference as tested in these kinetic experiments in $\mathrm{CHO}$ transfectants does not explain the reduced expression of DAF in $\mathrm{Dr}^{\mathrm{b}}$ erythrocytes. There are two broad classes of explanations for this finding: either the reduced ex- pression does not map to the same variation causing the allelic difference (e.g., there is a second change, perhaps in the regulatory region of the gene, that leads to reduced transcription), or the CHO transfectant system does not reproduce the conditions causing the reduced expression in human erythrocytes. Since two separate, widely spaced mutations seem less likely a priori, one has to consider the many differences that arise in comparing the $\mathrm{CHO}$ cells and the erythrocytes. Some of the major considerations are: $(a)$ the altered amino acid might result in a change in posttranslational processing (since it is a serine to leucine change, loss of $O$-linked glycosylation is possible) in human cells that is not reproduced faithfully in the $\mathrm{CHO}$ cells; $(b)$ the tissue culture system in general does not match the in vivo blood stream conditions; and $(c)$ the $\mathrm{CHO}$ cell type (and perhaps all nucleated cells) is not a good model for the erythrocyte as far as DAF expression and stability. In regard to this latter point, it should be noted that the reduced expression of $\mathrm{Dr}^{\mathrm{b}}$ DAF has only been documented on human erythrocytes, so investigation of human leukocytes should also be an avenue for future study of this question.

The final impact of the studies reported here is in the area of serological analysis that forms part of the foundations of immunohematology. Through the use of allele-specific RFLP analysis we can phenotype individuals at the DAF Dr polymorphic locus (Fig. 4). This was made possible in the present situation because the polymorphism involved the loss of a Taq I restriction endonuclease site, but if this were not available the DNA sequence difference could be ascertained by hybridization with allele-specific oligonucleotides. That approach has been used extensively for typing polymorphic HLA loci (55).

The more common problem in immunohematology than the identification of alloantigen specificity (phenotyping) is the identification of alloantibody. The system that we have established with AST allows that alloantibody analysis as demonstrated by either of two assays, inhibition of hemagglutination (Table III) or flow cytometry (Fig. 6). In the present case they allowed us to come full circle and confirm the molecular basis of the polymorphism using the alloantisera to $\mathrm{Dr}^{\mathrm{a}}$ that originally defined the polymorphism. In the general case they would allow serological analysis of any alloantiserum. One of the major advantages of this approach using AST is that only a single allele of one blood group system is expressed by each AST in a foreign cell background that lacks all of the other blood group antigens of that or other systems. Therefore one can test an alloantiserum that might contain multiple erythrocyte alloantibodies (and possibly also an autoantibody) against an AST and get an answer regarding the specific allele of that AST. Similar testing against human erythrocytes is ambiguous because the erythrocytes express multiple alloantigens. As the major human blood group systems are cloned, one could create a panel of AST covering most or all of the clinically important systems, allowing identification of all of the specificities in a complex alloantiserum. Neither of the two assays that were used in this study would be the most practical for routine use in serological analysis in the clinical laboratory, but they could be replaced with other methods of testing the alloantiserum versus the AST, such as agglutination reactions or some form of enzyme-linked immunoassay. The actual demonstration in this report that one can use allele-specific RFLP and allele-specific transfectants for the analysis of erythrocyte alloantigens and alloantibodies, respectively, opens up a new molecular approach to immunohematology. 


\section{Acknowledgments}

We thank Miguel Arce and Katharine Coyne for expert technical assistance, Kelli Simburger for oligonucleotide synthesis, and Julie Negrete for expert assistance in preparation of the manuscript.

This work was supported by grants from the National Institutes of Health (AI-15322) and from the American Association of Blood Banks Foundation to D. Lublin, and by grants HL-33572 and HL-44042 from the NIH to M. Telen. Dr. Telen is the recipient of Research Career Development Award HL-02233 from the NIH.

\section{References}

1. Lublin, D. M., and J. P. Atkinson. 1989. Decay-accelerating factor: bio chemistry, molecular biology, and function. Annu. Rev. Immunol. 7:35-58.

2. Lublin, D. M., R. S. Lemons, M. M. LeBeau, V. M. Holers, M. L. Tykocinski, M. E. Medof, and J. P. Atkinson. 1987. The gene encoding decay-accelerating factor (DAF) is located in the complement-regulatory locus on the long arm of chromosome 1. J. Exp. Med. 165:1731-1736.

3. Rey-Campos, J., P. Rubinstein, and S. Rodriguez de Cordoba. 1987. Decay-accelerating factor. Genetic polymorphism and linkage to the RCA (regulator of complement activation) gene cluster in humans. J. Exp. Med. 166:246-252.

4. Kinoshita, T., M. E. Medof, R. Silber, and V. Nussenzweig. 1985. Distribution of decay-accelerating factor in the peripheral blood of normal individuals and patients with paroxysmal nocturnal hemoglobinuria. J. Exp. Med. 162:7592.

5. Nicholson-Weller, A., J. P. March, C. E. Rosen, D. B. Spicer, and K. F. Austen. 1985. Surface membrane expression by human blood leukocytes and platelets of decay-accelerating factor, a regulatory protein of the complement system. Blood. 65:1237-1244.

6. Medof, M. E., E. I. Walter, J. L. Rutgers, D. M. Knowles, and V. Nussenzweig. 1987. Identification of the complement decay-accelerating factor (DAF) on epithelium and glandular cells and in body fluids. J. Exp. Med. 165:848-864

7. Asch, A. S., T. Kinoshita, E. A. Jaffe, and V. Nussenzweig. 1986. Decay-accelerating factor is present on cultured human umbilical vein endothelial cells. $J$. Exp. Med. 163:221-226.

8. Nicholson-Weller, A., J. Burge, D. T. Fearon, P. F. Weller, and K. F. Austen. 1982. Isolation of a human erythrocyte membrane glycoprotein with decay-accelerating activity for $\mathrm{C} 3$ convertases of the complement system. J. Immunol. 129:184-189.

9. Pangburn, M. K., R. D. Schreiber, and H. J. Muller-Eberhard. 1983. Deficiency of an erythrocyte membrane protein with complement regulatory activity in paroxysmal nocturnal hemoglobinuria. Proc. Natl. Acad. Sci. USA. 82:29802984.

10. Medof, M. E., T. Kinoshita, and V. Nussenzweig. 1984. Inhibition of complement activation on the surface of cells after incorporation of decay-accelerating factor (DAF) into their membranes. J. Exp. Med. 160:1558-1578.

11. Fujita, T., T. Inoue, K. Ogawa, K. lida, and N. Tamura. 1987. The mechanism of action of decay-accelerating factor (DAF). DAF inhibits the assembly of C3 convertases by dissociating C2a and Bb. J. Exp. Med. 166:1221-1228.

12. Davitz, M. A., M. G. Low, and V. Nussenzweig. 1986. Release of decayaccelerating factor (DAF) from the cell membrane by phosphatidylinositol-specific phospholipase C (PIPLC). Selective modification of a complement regulatory protein. J. Exp. Med. 163:1150-1161.

13. Medof, M. E., E. I. Walter, W. L. Roberts, R. Haas, and T. L. Rosenberry. 1986. Decay accelerating factor of complement is anchored to cells by a C-terminal glycolipid. Biochemistry. 25:6740-6747.

14. Low, M. G., and A. R. Saltiel. 1988. Structural and functional roles of glycosyl-phosphatidylinositol in membranes. Science (Wash. DC). 239:268-275.

15. Cross, G. A. M. 1990. Glycolipid anchoring of plasma membrane proteins. Annu. Rev. Cell. Biol. 6:1-39.

16. Holguin, M. H., L. A. Wilcox, N. J. Bernshaw, W. F. Rosse, and C. J. Parker. 1990. Erythrocyte membrane inhibitor of reactive lysis: effects of phosphatidylinositol-specific phospholipase $\mathrm{C}$ on the isolated and cell-associated protein. Blood. 75:284-289.

17. Sugita, Y., T. Tobe, E. Oda, M. Tomita, K. Yasukawa, N. Yamaji, T Takemoto, K. Furuichi, M. Takayama, and S. Yano. 1989. Molecular cloning and characterization of MACIF, an inhibitor of membrane channel formation of complement. J. Biochem (Tokyo). 106:555-557.

18. Davies, A., D. L. Simmons, G. Hale, R. A. Harrison, H. Tighe, P. J. Lachmann, and H. Waldmann. 1989. CD59, an Ly-6-like protein expressed in human lymphoid cells, regulates the action of the complement membrane attack complex on homologous cells. J. Exp. Med. 170:637-654.

19. Zalman, L. S., L. M. Wood, M. M. Frank, and H. J. Müller-Eberhard. 1987. Deficiency of the homologous restriction factor in paroxysmal nocturnal hemoglobinuria. J. Exp. Med. 165:572-577.
20. Hänsch, G. M., S. Schönermark, and D. Roelcke. 1987. Paroxysmal nocturnal hemoglobinuria type III: lack of an erythrocyte membrane protein restricting the lysis by C5b-9. J. Clin. Invest. 80:7-12.

21. Rosse, W. F., and C. Parker. 1985. Paroxysmal nocturnal haemoglobinuria. Clin. Haematol. 14:105-125.

22. Nicholson-Weller, A., J. P. March, S. I. Rosenfeld, and K. F. Austen. 1983. Affected erythrocytes of patients with paroxysmal nocturnal hemoglobinuria are deficient in the complement regulatory protein decay-accelerating factor. Proc. Natl. Acad. Sci. USA. 80:5066-5070.

23. Medof, M. E., T. Kinoshita, R. Silber, and V. Nussenzweig. 1985. Amelioration of lytic abnormalities of paroxysmal nocturnal hemoglobinuria with decay-accelerating factor. Proc. Natl. Acad. Sci. USA. 82:2980-2984.

24. Medof, M. E., D. M. Lublin, V. M. Holers, D. J. Ayers, R. R. Getty, J. F. Leykam, J. P. Atkinson, and M. L. Tykocinski. 1987. Cloning and characterization of cDNAs encoding the complete sequence of decay-accelerating factor of human complement. Proc. Natl. Acad. Sci. USA. 84:2007-2011.

25. Caras, I. W., M. A. Davitz, L. Rhee, G. Weddell, D. W. Martin, Jr., and V. Nussenzweig. 1987. Cloning of decay-accelerating factor suggests novel use of splicing to generate two proteins. Nature (Lond.). 325:545-549.

26. Post, T. W., M. A. Arce, M. K. Liszewski, E. S. Thompson, J. P. Atkinson, and D. M. Lublin. 1990. Structure of the gene for human complement protein decay accelerating factor. J. Immunol. 144:740-744.

27. Stafford, H. A., M. L. Tykocinski, D. M. Lublin, V. M. Holers, W. F. Rosse, J. P. Atkinson, and M. E. Medof. 1988. Normal polymorphic variations and transcription of the decay-accelerating factor gene in paroxysmal nocturnal hemoglobinuria cells. Proc. Natl. Acad. Sci. USA. 85:880-884.

28. Daniels, G. 1989. Cromer-related antigens-blood group determinants on decay-accelerating factor. Vox. Sang. 56:205-211.

29. Telen, M. J. S. E. Hall, A. M. Green, J. J. Moulds, and W. F. Rosse. 1988. Identification of human erythrocyte blood group antigens on decay-accelerating factor (DAF) and an erythrocyte phenotype negative for DAF. J. Exp. Med. 167:1993-1998.

30. Levene, C., N. Harel, G. Lavie, S. Greenberg, B. Laird-Fryer, and G. L. Daniels. 1984. A "new" phenotype confirming a relationship between $\mathrm{Cr}^{2}$ and Tc. Transfusion (Phila.). 24:13-15.

31. Levene, C., N. Harel, G. Kende, S. Papo, M. F. Bradford, and G. L. Daniels. 1987. A second Dr(a-) proposita with anti-Dre and a family with the Dr(a-) phenotype in two generations. Transfusion (Phila.). 1987. 27:64-65.

32. Seya, T., T. Farries, M. Nickells, and J. P. Atkinson. 1987. Additional forms of human decay-accelerating factor (DAF). J. Immunol. 139:1260-1267.

33. Lin, R. C., J. Herman, L. Henry, and G. L. Daniels. 1988. A family showing inheritance of the Inab phenotype. Transfusion (Phila.). 28:427-429.

34. Fambrough, D. M., A. G. Engel, and T. L. Rosenberry. 1982. Acetylcholinesterase of human erythrocytes and neuromuscular junctions: homologies revealed by monoclonal antibodies. Proc. Natl. Acad. Sci. USA. 79:1082-1086.

35. Sanchez, M. F., A. M. Krensky, C. F. Ware, E. Robbins, J. L. Strominger, S. J. Burakoff, and T. A. Springer. 1982. Three distinct antigens associated with human T-lymphocyte-mediated cytolysis: LFA-1, LFA-2, and LFA-3. Proc. Natl. Acad. Sci. USA. 79:7489-7493.

36. Chow, F. L., M. J. Telen, and W. F. Rosse. 1985. The acetylcholinesterase defect in paroxysmal nocturnal hemoglobinuria: evidence that the enzyme is absent from the cell membrane. Blood. 66:940-945.

37. Telen, M. J., R. M. Scearce, and B. F. Haynes. 1987. Human erythrocyte antigens III. Characterization of a panel of murine monoclonal antibodies that react with human erythrocyte and erythroid precursor membranes. Vox Sang. 52:236-243.

38. Rosse, W. F., and J. V. Dacie. 1966. Immune lysis of normal human and paroxysmal nocturnal hemoglobinuria (PNH) red blood cells. I. The sensitivity of PNH red cells to lysis by complement and specific antibody. J. Clin. Invest. 45:736-744.

39. Boyum, A., 1968. Isolation of mononuclear cells and granulocytes from human blood. Scand. J. Clin. Lab. Invest. Suppl. 21:77-89.

40. Higuchi, R. 1989. Simple and rapid preparation of samples for PCR. In PCR Technology: Principles and Applications for DNA Amplification. H. A. Erlich, editor. Stockton Press, New York. 31-38.

41. Saiki, R. K., D. H. Gelfand, S. Stoffel, S. J. Scharf, R. Higuchi, G. T. Horn, K. B. Mullis, and H. A. Erlich. 1988. Primer-directed enzymatic amplification of DNA with a thermostable DNA polymerase. Science (Wash. DC). 239:487-491.

42. Sambrook, J., E. F. Fritsch, and T. Maniatis. 1989. Molecular Cloning: A Laboratory Manual. 2nd edition. Cold Spring Harbor Laboratory, Cold Spring Harbor, New York.

43. Chen, E. Y., and P. H. Seeburg. 1985. Supercoil sequencing: a fast and simple method for sequencing plasmid DNA. DNA (NY). 4:165-170.

44. Tabor, S., and C. C. Richardson. 1987. DNA sequence analysis with a modified bacteriophage T7 DNA polymerase. Proc. Natl. Acad. Sci. USA. 84:4767-4771.

45. Fuhlbrigge, R. C., S. M. Fine, E. R. Unanue, and D. D. Chaplin. 1988. Expression of membrane interleukin 1 by fibroblasts transfected with murine pro-interleukin 1 alpha cDNA. Proc. Natl. Acad. Sci. USA. 85:5649-5653. 
46. Felgner, P. L., T. R. Gadek, M. Holm, R. Roman, H. W. Chan, M. Wenz, J. P. Northrop, G. M. Ringold, and M. Danielsen. 1987. Lipofection: a highly efficient, lipid-mediated DNA-transfection procedure. Proc. Natl. Acad. Sci. USA. 84:7413-7417.

47. Bordier, C. 1981. Phase separation of integral membrane proteins in Triton X-114 solution. J. Biol. Chem. 256:563-567.

48. Lublin, D. M., J. Krsek-Staples, M. K. Pangburn, and J. P. Atkinson. 1986. Biosynthesis and glycosylation of the human complement regulatory protein decay-accelerating factor. J. Immunol. 137:1629-1635.

49. Sugita, Y., T. Negoro, T. Matsuda, T. Sakamoto, and M. Tomita. 1986. Improved method for the isolation and preliminary characterization of human DAF (decay accelerating factor). J. Biochem. 100:143-150.

50. Telen, M. J., G. S. Eisenbarth, and B. F. Haynes. 1983. Human erythrocyte antigens: regulation of expression of a novel human erythrocyte surface antigen by the inhibitory Lutheran $\operatorname{In}(\mathrm{Lu})$ gene. J. Clin. Invest. 71:1878-1886.

51. Saiki, R. K., T. L. Bugawan, G. T. Horn, K. B. Mullis, and H. A. Erlich 1986. Analysis of enzymatically amplified $\beta$-globin and HLA-DQ $\alpha$ DNA with allele-specific oligonucleotide probes. Nature (Lond.). 324:163-166.
52. Kunkel, T. A. 1985. Rapid and efficient site-directed mutagenesis without phenotypic selection. Proc. Natl. Acad. Sci. USA. 82:488-492.

53. Telen, M. J., and A. M. Green. 1989. The Inab phenotype: characterization of the membrane protein and complement regulatory defect. Blood. 74:437441.

54. Merry, A. H., V. I. Rawlinson, M. Uchikawa, M. R. Daha, and R. B. Sim. 1989. Studies on the sensitivity to complement-mediated lysis of erythrocytes (Inab phenotype) with a deficiency of DAF (decay accelerating factor). Br. $J$. Haemotol. 73:248-253.

55. Scharf, S. J., A. Friedman, C. Brautbar, F. Szafer, L. Steinman, G. Horn, U. Gyllensten, and H. A. Erlich. 1988. HLA class II allelic variation and susceptibility to pemphigus vulgaris. Proc. Natl. Acad. Sci. USA. 85:3504-3508.

56. Kinoshita, T., S. I. Rosenfeld, and V. Nussenzweig. 1987. A high m.w. form of decay-accelerating factor (DAF-2) exhibits size abnormalities in paroxysmal nocturnal hemoglobinuria erythrocytes. J. Immunol. 138:2994-2998.

57. Spring, F. A., P. A. Judson, G. L. Daniels, S. F. Parsons, G. Mallinson, and D. J. Anstee. 1987. A human cell surface glycoprotein that carries Cromer-related blood group antigens on erythrocytes is also expressed on leukocytes and platelets. Immunology. 62:307-313. 